\title{
Contribution of Glucosylceramide Synthase to the Proliferation of Mouse Osteoblasts
}

\author{
YOSHITAKA MISHIMA ${ }^{1,2}$, KAZUNORI HAMAMURA ${ }^{1}$, HANAMI KATO ${ }^{1,2}$, \\ KOICHI FURUKAWA ${ }^{3}$, YUKO TASHIMA ${ }^{4}$, TETSUYA OKAJIMA ${ }^{4}$, HISATAKA KONDO ${ }^{1}$, \\ TAKUMA SATO ${ }^{2}$, KEN MIYAZAWA ${ }^{2}$, SHIGEMI GOTO ${ }^{2}$ and AKIFUMI TOGARI ${ }^{1}$ \\ ${ }^{1}$ Department of Pharmacology, School of Dentistry, Aichi Gakuin University, Nagoya, Japan; \\ ${ }^{2}$ Department of Orthodontics, School of Dentistry, Aichi Gakuin University, Nagoya, Japan; \\ ${ }^{3}$ Department of Biomedical Sciences, Chubu University College of Life and Health Sciences, Kasugai, Japan; \\ ${ }^{4}$ Department of Molecular Biochemistry, Nagoya University Graduate School of Medicine, Nagoya, Japan
}

\begin{abstract}
Background/Aim: Glycosphingolipids are known to be involved in bone metabolism. However, their roles and regulatory mechanisms in osteoblast proliferation are largely unknown. In this study, we examined the effects of inhibitors of glucosylceramide synthase (GCS), which is responsible for the generation of all glycosphingolipids, on osteoblast proliferation. Materials and Methods: We analyzed the expression of glycosphingolipids and cell growth in MC3T3E1 mouse osteoblast cells treated with the GCS inhibitors miglustat, D-PDMP and D-PPMP. We also conducted microarray analysis and RNA interference to identify genes involved in cell growth regulated by GCS. Results: Glycosphingolipids GDIa and Gb4 expressed in MC3T3-E1 cells, were suppressed by GCS inhibitors. Furthermore, the proliferation of MC3T3-El cells was suppressed by the inhibitors. Using microarray analysis, we predicted nine genes (Fndc1, Acta2, Igfbp5, Cox6a2, Cth, Mymk, Angptl6, Mab2112, and Igsf10) suppressed by all three inhibitors. Furthermore, partial silencing of Angptl6 by RNA interference reduced MC3T3-E1 cell growth. Conclusion: These results show that GCS regulates proliferation through Angptl6 in osteoblasts.
\end{abstract}

Glycosphingolipids consist of carbohydrate chains and ceramides, comprising of fatty acids and long chain bases

This article is freely accessible online.

Correspondence to: Kazunori Hamamura, Ph.D., DDS, Department of Pharmacology, School of Dentistry, Aichi Gakuin University, 1100 Kusumoto-cho, Chikusa-ku, Nagoya 464-8650, Japan. Tel: +81 527576743, Fax: +81 527525988, email: hamak@dpc.agu.ac.jp

Key Words: Glycosphingolipids, glucosylceramide synthase, osteoblasts, cell proliferation. such as sphingosine, and are classified into four main series: ganglio, globo, lacto and neolacto. These glycosphingolipids are known to be involved in the maintenance of homeostasis in organisms and the pathogenesis of various diseases (1-4). Ganglio- and globo-series glycosphingolipids have also been reported to be involved in the regulation of bone metabolism. For example, deletion of ganglio-series GD3 synthase in mice results in the prevention of bone loss with aging via the attenuation of bone resorption through the reduction of osteoclast numbers (5). Ganglio-series GD1a has been reported to be expressed in osteoblasts and mesenchymal stem cells (MSCs) and to regulate differentiation of MSCs to osteoblasts (6-8). Recently, we reported that globo-series Gb4 is expressed in human and mouse osteoblasts and demonstrated that deficiency of Gb4 in mice decreased bone mass through the suppression of bone formation (9).

Glucosylceramide synthase (GCS), which is encoded by the UDP-glucose ceramide glucosyltransferase gene $(\mathrm{Ugcg})$, transfers glucose to ceramide, resulting in glucosylceramide production $(10,11)$. Since GCS catalyzes the initial step in the biosynthesis of almost all glycosphingolipids (Figure 1A), inhibitors of GCS and mice with genetic deletion of $U g c g$ have been used for the elucidation of the role of glycoshingolipids in the development and function of various tissues and organs. For example, forebrain neuron-specific deletion of $U g c g$ in mice causes obesity, hypothermia, and lower sympathetic activity (12), indicating that neuronal expression of GCS is important for energy homeostasis (12). As enterocytes in mice with enterocyte-specific deletion of $U g c g$ lack brush borders, GCS has also been reported to be important for intestinal endocytic function (13). Furthermore, $U g c g$ expression is involved in the proliferation of mouse embryonic stem cells (mESCs) and differentiation of mESCs to neural cells (14). GCS was also reported to determine differentiation of MSCs to osteoblasts or adipocytes (15). On 


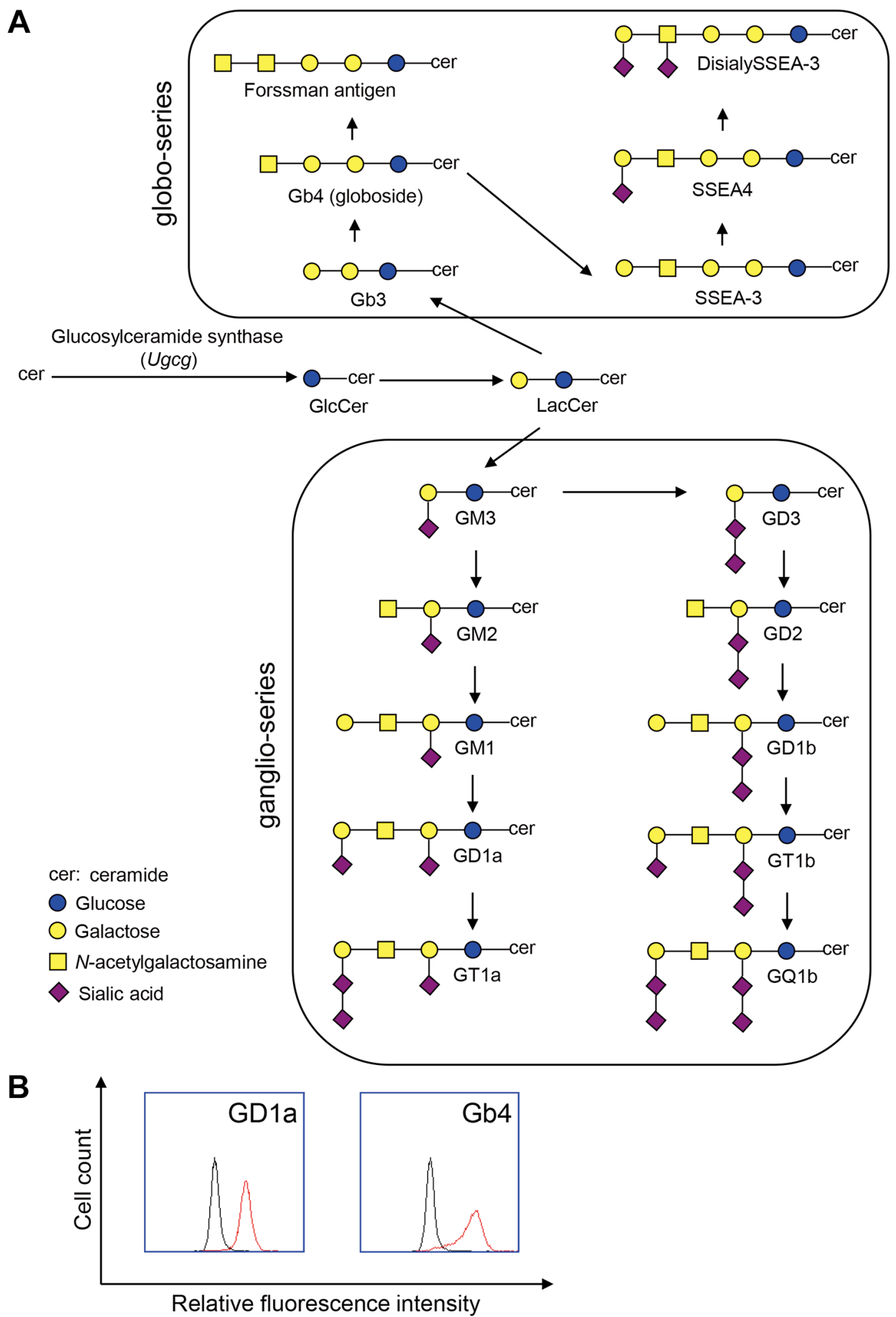

Figure 1. Synthetic pathway of ganglio- and globo-series glycosphingolipids, and expression of glycosphingolipids GD1a and Gb4 in MC3T3-E1 cells. (A) Synthetic pathway of ganglio- and globo-series glycosphingolipids. (B) Expression of ganglio-series glycosphingolipid GD1a and globoseries glycosphingolipid Gb4 in MC3T3-E1 cells by flow cytometric analysis. Red line: presence of primary antibody (anti-GD1a or Gb4 monoclonal antibody) and secondary antibody (FITC-conjugated anti-mouse IgM or anti-human IgM), gray line: absence of primary antibody and presence of secondary antibody (FITC-conjugated anti-mouse IgM or anti-human IgM). 
Table I. Real-time PCR primers used in this study.

\begin{tabular}{|c|c|c|}
\hline Target & Forward primer & Backward primer \\
\hline Osteocalcin & 5'-CCGGGAGCAGTGTGAGCTTA-3' & 5'-AGGCGGTCTTCAAGCCATACT-3' \\
\hline Ugcg & 5'- ТСTTCTTCATGTGCCACTGC -3, & 5'- CCTGTAGCGACCAGTTCTCC -3' \\
\hline Fnde1 & 5'- CTGGTCATGGGGTTCTGACT -3' & 5'- AGCTGGTGGTAGGCTGAAGA -3' \\
\hline Acta2 & 5'- TGTGCTGGACTCTGGAGATG -3' & 5'- ATCTCACGCTCGGCAGTAGT -3' \\
\hline Igfbp5 & 5'- GGTTTGCCTCAACGAAAAGA -3, & 5'- CTGGGTCAGCTTCTTTCTGC -3' \\
\hline Cox6a2 & 5'- GACCTTTGTGCTGGCTCTTC -3' & 5'- ATTGTGGAAAAGCGTGTGGT -3' \\
\hline Cth & 5'- TACTTCAGGAGGGTGGCATC -3' & 5'- TCCAATGTCAGCCAACTTCA -3' \\
\hline Mymk & 5'- ACTGGCCGACTTTGATGAAC -3' & 5'- ATGCTCTTGTCGGGGTACAG -3' \\
\hline Angpt16 & 5'- AGACTCCCTCTCTTGGCACA -3, & 5'- CAGTAGACCCCGTCCTGGTA -3, \\
\hline Mab21I2 & 5'-TGTGCCGTGCTCAAACTAAG-3' & 5'-TAGTGTCGGCGATCATCTTG-3' \\
\hline $\operatorname{Igsf} 10$ & 5'- AGCACTCAAGGGACCTGCTA -3' & 5'- AGCTTTGGGGAGGGTAGTGT -3' \\
\hline $\operatorname{Mtg} 2$ & 5'- AGGAGGAAAAGGCAATCGTT -3' & 5'- GGCTCGAAGGAGAGAGGATT -3' \\
\hline Nr4a1 & 5' - CTTGAGTTCGGCAAGCCTAC -3' & 5'- AGGCAGAGGAACAAGCTGAG -3' \\
\hline Mapre2 & 5'- CAAGCAAAGTTGGAGCATGA -3' & 5'- GATCGTACTCCTTCCCGTCA -3' \\
\hline Ahcyl1 & 5'- TTTCCATCACGGCTACAACA -3' & 5'- AGTTCTGTCAGGTGGGCATC -3' \\
\hline Exoc6b & 5'- TGAGGAACATGGACGATTCA -3' & 5'- CCGTCACCTGGTTTTTGAGT -3' \\
\hline Traf6 & 5'- AAACCACGAAGAGGTCATGG -3' & 5'- GCGGGTAGAGACTTCACAGC -3' \\
\hline Anxa3 & 5'- AGAACAAATGGGGCACAGAC -3' & 5'- GAGTGTTCCTCGCACAATGA -3' \\
\hline Egr1 & 5'- GAGTTATCCCAGCCAAACGA -3' & 5'- GGCAGAGGAAGACGATGAAG -3' \\
\hline Egr2 & 5'- AGGAGGTTCTCACGCTCTGA -3' & 5'- GCTTCCTTTCGTCACTCCTG -3' \\
\hline Egr3 & 5'- AGACGTGGAGGCCATGTATC -3' & 5'- GGGAAAAGATTGCTGTCCAA -3' \\
\hline Gapdh & 5'-TGCACCACCAACTGCTTAG-3' & 5'-GGATGCAGGGATGATGTTC-3' \\
\hline
\end{tabular}

the other hand, since glycosphingolipids are involved in the pathogenesis of various diseases, it has been reported that suppression of glycosphingolipids by GCS inhibitors results in amelioration of the diseases. For example, GCS inhibitors attenuate hepatic steatosis (16). Furthermore, GCS inhibitors were reported to prolong life through the decrease of glucosylceramide accumulation in a mouse model of type 2 Gaucher disease (17). However, there are no reports about the role of GCS in osteoblast proliferation.

To evaluate the involvement of glycosphingolipids in the proliferation of osteoblasts, we analyzed the effects of three GCS inhibitors on cell growth. We also examined the effects of the inhibitors on the expression of GD1a and Gb4 in MC3T3-E1 mouse osteoblast cells by flow cytometry. To identify regulatory molecule(s) of cell proliferation regulated by GCS in MC3T3-E1 cells, we conducted genome-wide microarray analysis. mRNA expression profiles were evaluated in four groups of samples (control, miglustat treatment, D-PDMP treatment and D-PPMP treatment), showing that some genes are likely to be involved in the proliferation of MC3T3-E1 cells. We employed RNA interference to examine whether the predicted genes are involved in the proliferation of osteoblasts. We found that inhibition of GCS in osteoblasts results in the suppression of proliferation. To the best of our knowledge, this is the first study to show that GCS regulates the proliferation of osteoblasts through a new proliferation regulatory molecule identified by genome-wide microarray analysis.

\section{Materials and Methods}

Cell culture. MC3T3-E1 mouse osteoblast cells were grown in $\alpha$ Minimum Essential Medium ( $\alpha$-MEM) (Wako Pure Chemical Industries, Ltd., Osaka, Japan) containing 10\% fetal bovine serum (Sigma-Aldrich, St. Louis, MO, USA) and antibiotics $(100 \mathrm{U} / \mathrm{mL}$ penicillin, $100 \mu \mathrm{g} / \mathrm{mL}$ streptomycin; Wako Pure Chemical Industries, Ltd.) at $37^{\circ} \mathrm{C}$ with $5 \% \mathrm{CO}_{2}$ in a humidified incubator.

Antibodies. Anti-GD1a monoclonal antibody (mAb) D266 was previously generated in Dr. Furukawa's laboratory. Anti-Gb4 mAb HIRO34 was kindly provided by Dr. Makoto Uchikawa of the Japanese Red Cross Tokyo Blood Center (Tokyo, Japan). FITCconjugated anti-mouse IgM antibody was obtained from Affymetrix eBioscience (San Diego, CA, USA) while FITC-conjugated antihuman IgM from BioLegend (San Diego, CA, USA).

Induction towards mature osteoblasts. Confluent MC3T3-E1 cells were treated with $50 \mu \mathrm{g} / \mathrm{mL}$ ascorbic acid (Wako Pure Chemical Industries, Ltd.) and $5 \mathrm{mM} \beta$-glycerophosphate (Sigma-Aldrich). The medium was changed every other day. qPCR was conducted after 7,14 and 21 days in culture, and flow cytometry was conducted after 14 days in culture. Osteocalcin was used as the marker of osteoblast differentiation.

Flow cytometry. Cell surface expression of GD1a and Gb4 was analyzed by Accuri ${ }^{\mathrm{TM}}$ C6 Flow Cytometer (BD Biosciences, San Jose, CA, USA) using antibodies against GD1a (mouse IgM, D266) and Gb4 (human IgM, HIRO34). The cells were incubated for 1 hour with primary antibodies followed by incubation with FITC-conjugated anti-mouse IgM or anti-human IgM for $45 \mathrm{~min}$ on ice. Control cells for flow cytometry were used with the secondary antibody alone (9). 

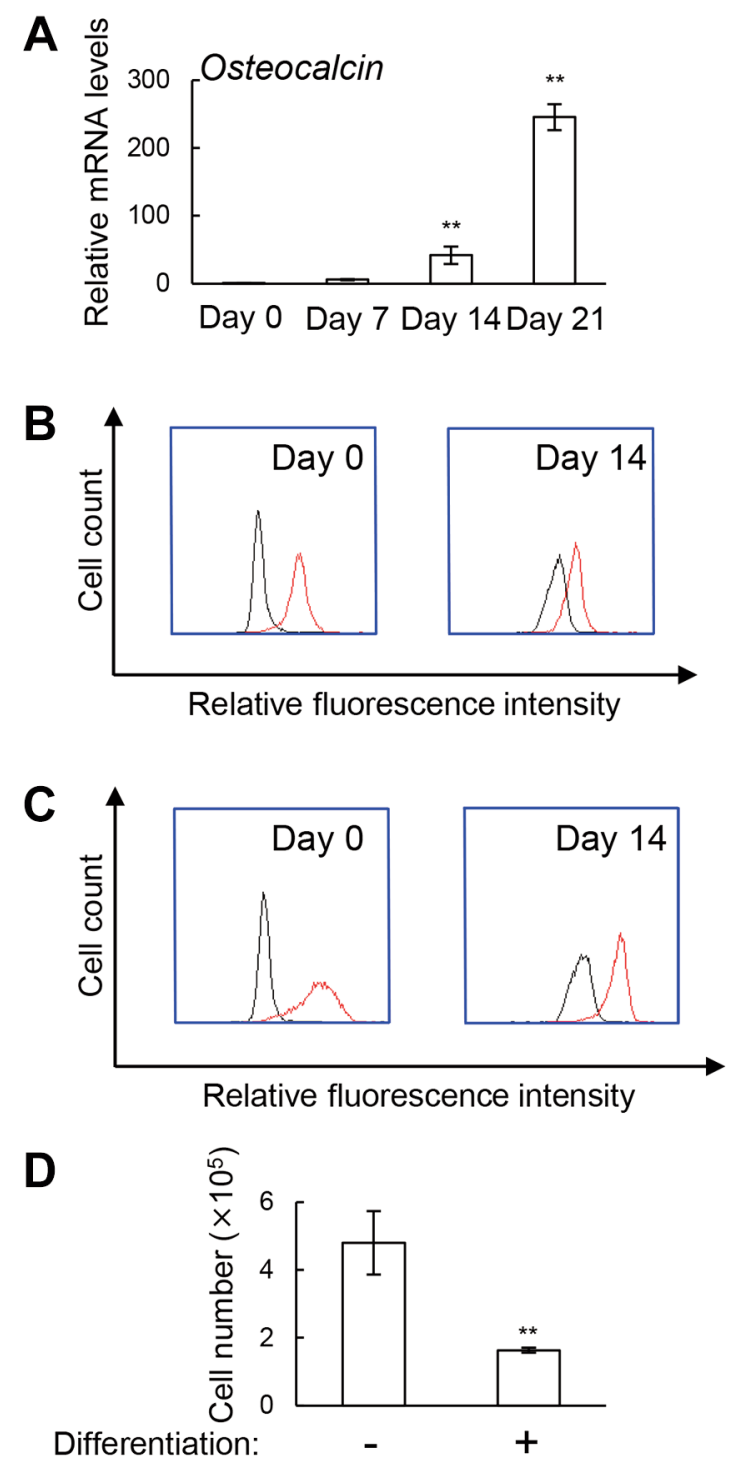
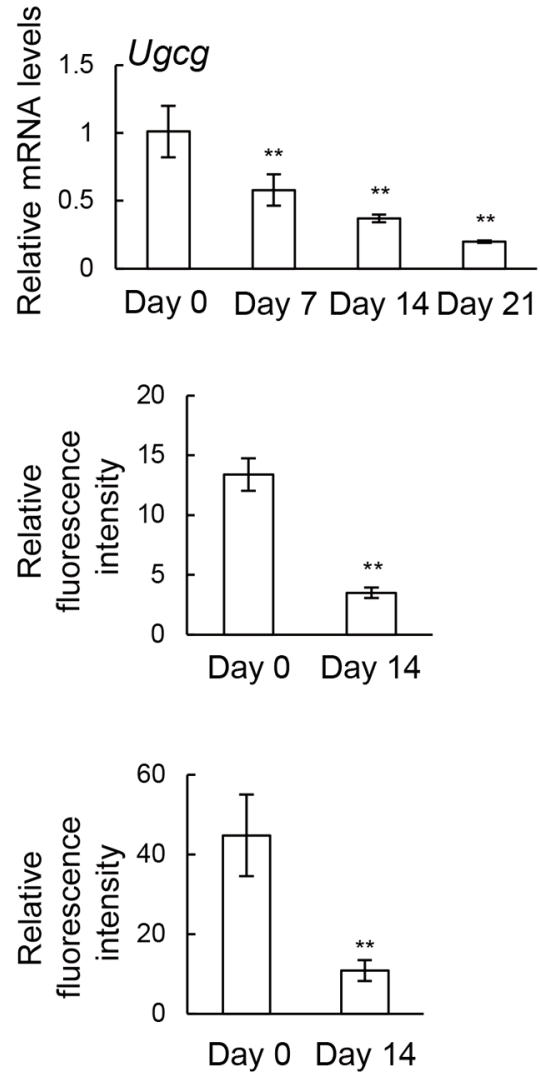

Figure 2. Expression levels of GCS gene Ugcg, GDIa, and Gb4 after induction of osteoblastogenesis. (A) mRNA expression of Osteocalcin and Ugcg in MC3T3-E1 cells on days 0, 7, 14 and 21 after induction of osteoblastogenesis ( $n=4)$. (B) Expression of GD1a in MC3T3-E1 cells on days 0 and 14 after induction of osteoblastogenesis by flow cytometric analysis $(n=5)$. Gray line: in the absence of anti-GDla antibody and in the presence of FITC-conjugated anti-mouse IgM. Red line: in the presence of anti-GDIa antibody and FITC-conjugated anti-mouse IgM. The relative expression level of GDI a was defined as the ratio of the fluorescence intensity in the red line to the fluorescence intensity in the gray line. (C) Expression of Gb4 in MC3T3-E1 cells on days 0 and 14 after induction of osteoblastogenesis by flow cytometric analysis $(n=5)$. Gray line: absence of anti-Gb4 antibody and presence of FITC-conjugated anti-human IgM. Red line: presence of anti-Gb4 antibody and FITC-conjugated anti-human $I g M$. The relative expression level of Gb4 was defined as the ratio of the fluorescence intensity corresponding to the red line vs. the intensity in the gray line. (D) MC3T3-E1 cells before and after induction of osteoblastogenesis for 14 days were plated at $1.0 \times 10^{5} \mathrm{cells}$ per $60-\mathrm{mm}$ dish and cultured for 2 days. After staining the cells with trypan blue, the number of live cells was counted using a hemacytometer $(n=3)$. Data are expressed as mean \pm standard deviation. $* * p<0.01$.

Quantitative real-time PCR. The RNeasy Plus mini kit (Qiagen, Germantown, MD, USA) was used for extraction of total RNA. Reverse transcription was conducted with a high-capacity cDNA reverse transcription kit (Applied Biosystems, Carlsbad, CA, USA) to produce cDNA. qPCR was then performed using a TaKaRa Thermal Cycler Dice Real Time System III with the
THUNDERBIRD SYBR qPCR mix kit (TOYOBO, Osaka, Japan). Using the PCR primers listed in Table I, mRNA levels of Osteocalcin, Ugcg, Fndc1, Acta2, Igfbp5, Cox6a2, Cth, Mymk, Angptl6, Mab2112, Igsf10, Mtg2, Nr4a1, Mapre2, Ahcyl1, Exoc6b, Traf6, Anxa3, Egr1, Egr2 and Egr3 were determined, with Gapdh as an internal control. 

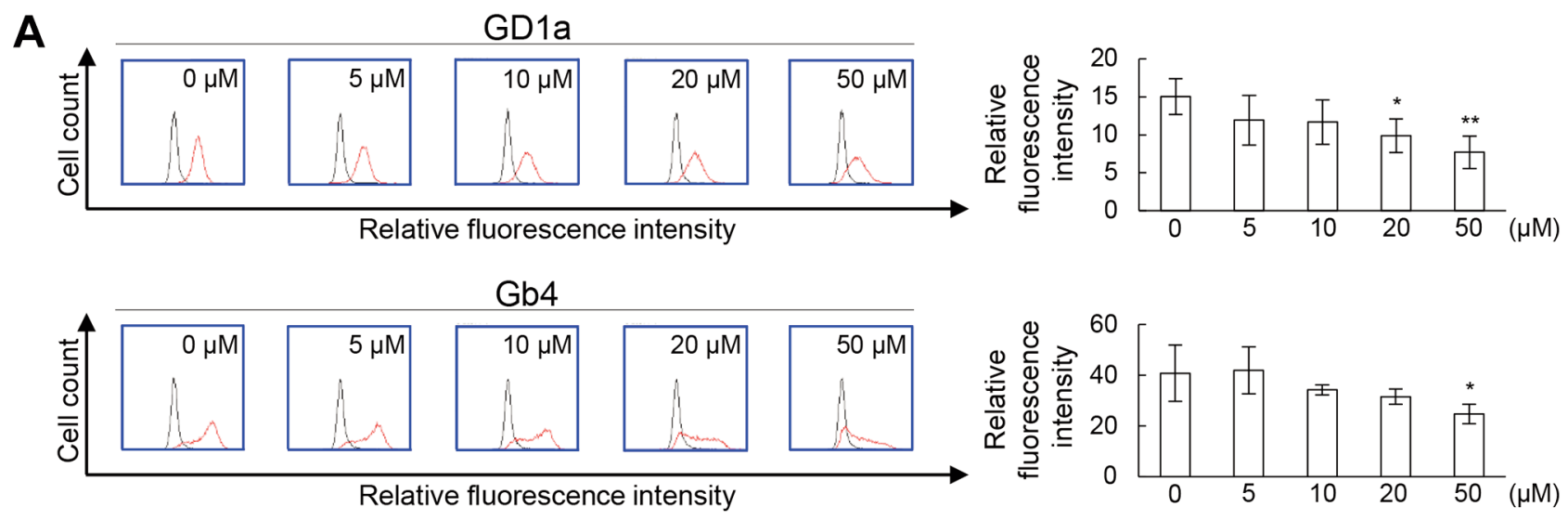

B
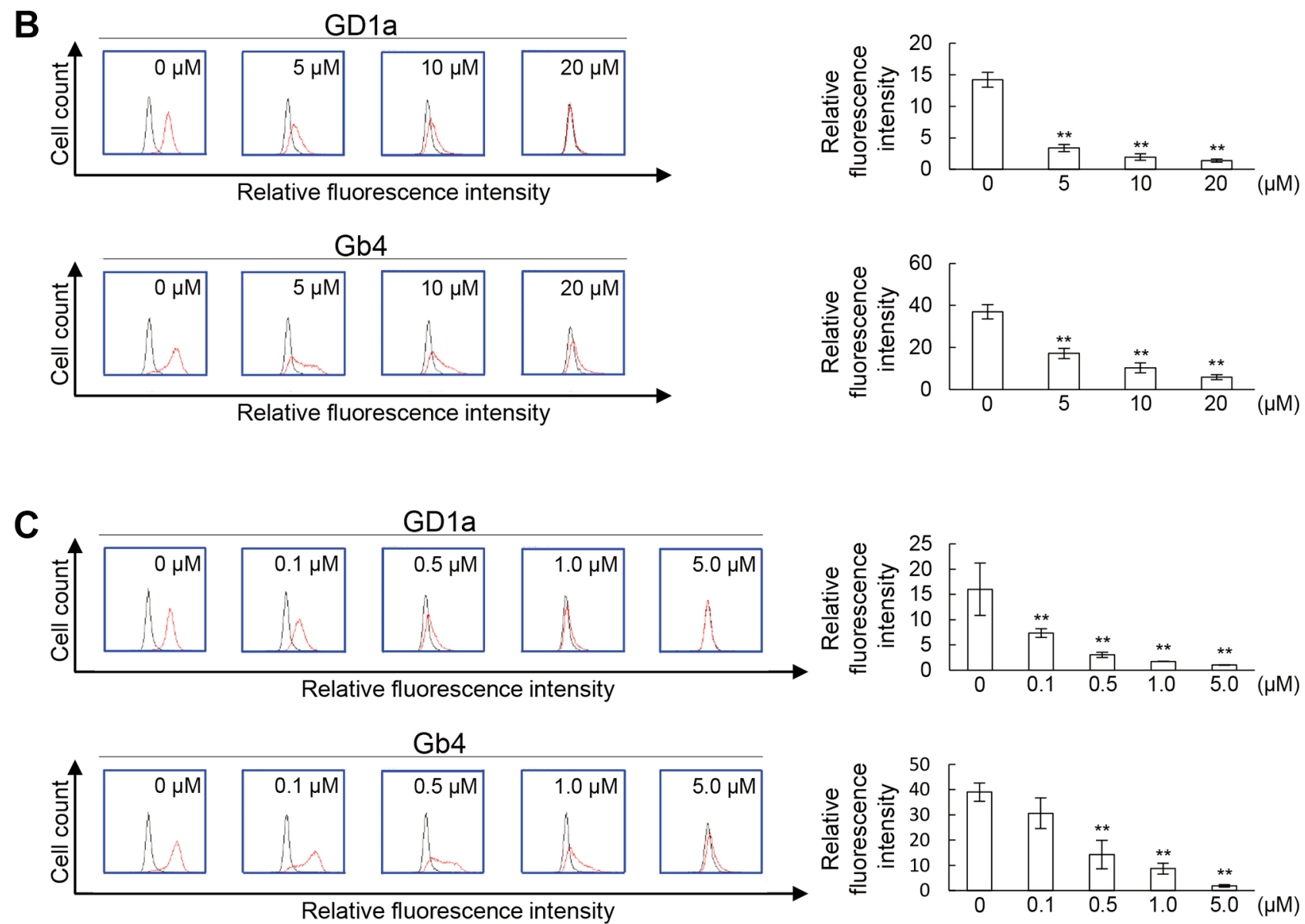

Figure 3. Suppression of GDla and Gb4 by miglustat, D-PDMP and D-PPMP in MC3T3-E1 cells. (A) Expression of GD1a and Gb4 in MC3T3-E1 cells on day 4 after treatment with miglustat $(5,10,20$ and $50 \mu M)$. (B) Expression of GD1a and Gb4 in MC3T3-E1 cells on day 4 after treatment with D-PDMP (5, 10 and $20 \mu M)$. (C) Expression of GDla and Gb4 in MC3T3-E1 cells on day 4 after treatment with D-PPMP (0.1, 0.5, 1.0 and $5.0 \mu \mathrm{M})$. Data are expressed as mean \pm standard deviation. ${ }^{*} p<0.05$ and $* * p<0.01$, respectively.

Treatment with GCS inhibitors and assay for cellular proliferation and death. After exposure to miglustat $(5,10,20$, and $50 \mu \mathrm{M}$; Wako Pure Chemical Industries, Ltd.) for 4 days, or D-PDMP (5, 10, and
$20 \mu \mathrm{M}$; Matreya LLC, State College, PA, USA) or D-PPMP (0.1, $0.5,1.0$, and $5.0 \mu \mathrm{M}$; Matreya LLC) for 3 days, the cells were plated at $1.0 \times 10^{5}$ cells per $60-\mathrm{mm}$ dish, and cultured for 2 days. 
A

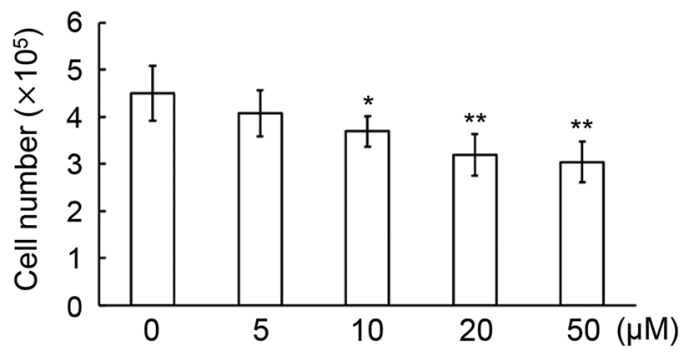

C

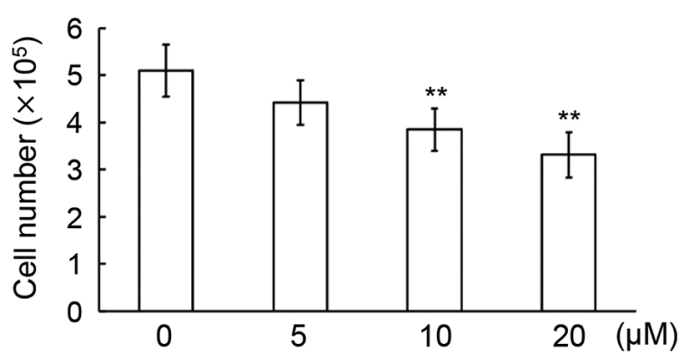

E

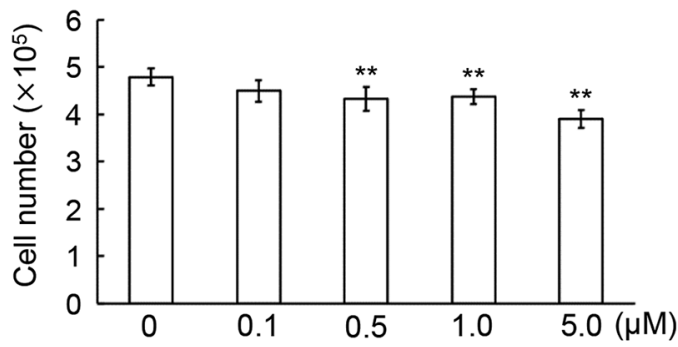

B

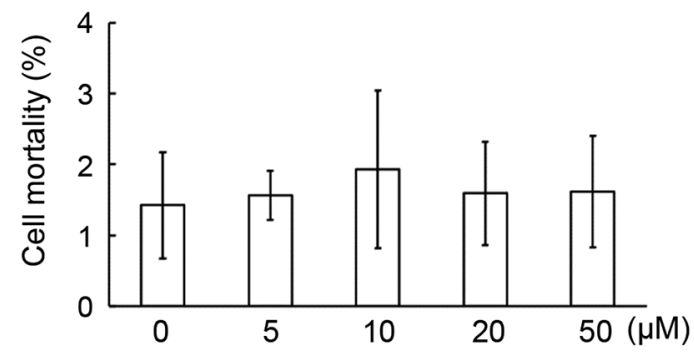

D

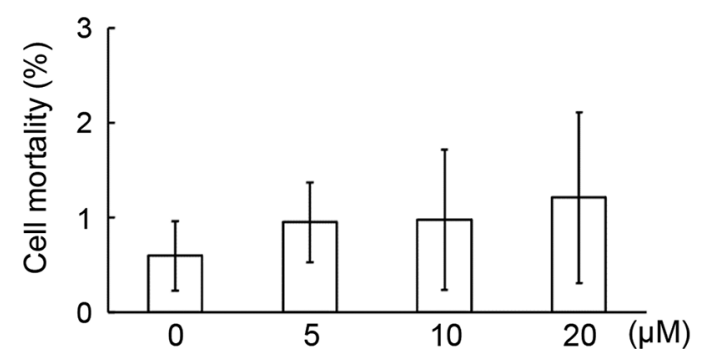

$\mathbf{F}$

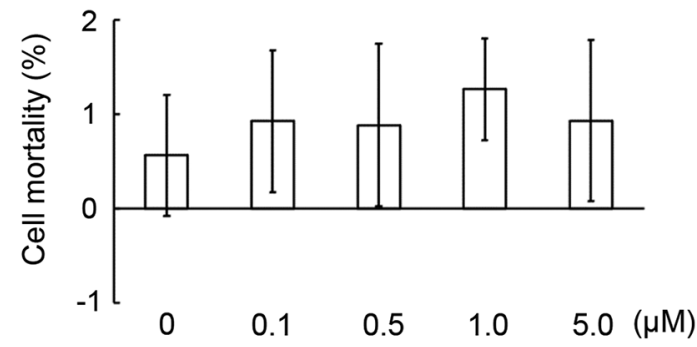

Figure 4. Effects of miglustat, D-PDMP and D-PPMP on the proliferation and mortality rate of MC3T3-E1 cells. (A, B) After exposure to 5, 10, 20 , and $50 \mu \mathrm{M}$ miglustat for 4 days, the cells were plated at $1.0 \times 10^{5}$ cells per 60-mm dish and cultured for 2 days. After staining the cells with trypan blue, the number of live $(A)$ and dead (B) cells was counted using a hemacytometer. (C, D) After exposure to 5, 10 and $20 \mu M D$-PDMP for 3 days, the cells were plated at $1.0 \times 10^{5}$ cells per 60-mm dish and cultured for 2 days. After staining the cells with trypan blue, the number of live $(C)$ and dead (D) cells was counted using a hemacytometer. $(E, F)$ After exposure to 0.1, 0.5, 1.0 and $5.0 \mu M$ D-PPMP for 3 days, the cells were plated at $1.0 \times 10^{5}$ cells per 60-mm dish and cultured for 2 days. After staining the cells with trypan blue, the number of live $(E)$ and dead $(F)$ cells was counted using a hemacytometer. Data are expressed as mean \pm standard deviation. $* p<0.05$ and $* * p<0.01$.

After staining with trypan blue, the number of live and dead cells was counted using a hemacytometer.

Microarray analysis. Genome-wide expression analysis was conducted using RNA from MC3T3-E1 cells (SurePrint G3 Mouse GE microarray $8 \times 60 \mathrm{~K}$ Ver3.0; Agilent, Santa Clara, CA, USA). Intensity values of each scanned feature were quantified using Agilent's feature extraction software version 12.1.1.1, which performs background subtractions. We only used features which were flagged as no errors (Detected flags) and excluded features which were not positive, not significant, not uniform, not above background, saturated and population outliers (not detected and compromised flags). Normalization was performed using Agilent GeneSpring software version 14.9.1 (per chip: normalization to 75 percentile shift). Heatmap and cluster analysis were performed with sorted datasets by Pearson's correlation on Average Method with selected probe sets. The four groups for the MC3T3-E1 cells (cells were not treated with ascorbic acid and $\beta$-glycerophosphate) were control, miglustat, D-PDMP and D-PPMP. The concentrations of miglustat, D-PDMP and D-PPMP were 50, 10 and $1.0 \mu \mathrm{M}$, respectively. Four days after treatment with the inhibitors, the cells were plated at $2.5 \times 10^{5}$ cells per $60-\mathrm{mm}$ dishes and cultured for 24 $\mathrm{h}$ before harvesting for microarray analysis. The microarray data was deposited in NCBI GEO (accession number: GSE174323).

Knockdown of Angptl6, Cox6a2, Cth, and Fndc1 by siRNA. MC3T3-E1 cells were treated with siRNA specific to Angpt16 (5'CUC AUA UUC UGG UAA CUG U-3'; Life Technologies), Cox6a2 (5'-GCC CAG AGU UCA UCC CGU A-3'; Life Technologies), Cth (5'-GGA UCG AAA CAC CCA CAA A-3'; Life Technologies), and Fndc1 (5'-GGA CUA UGU UGU AUA CGA U3'; Life Technologies). As a non-specific control, a negative control 


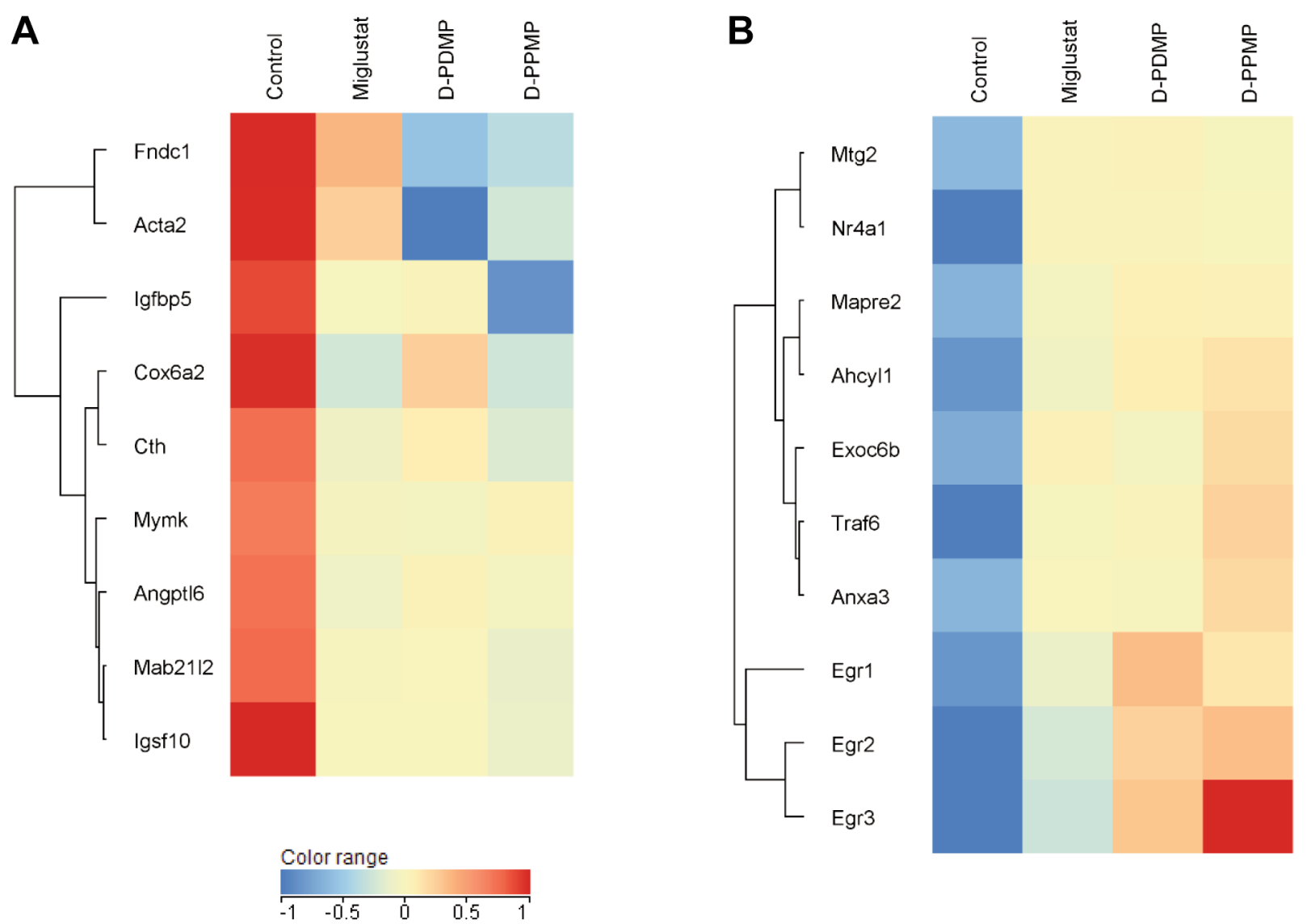

Figure 5. Heatmaps showing the genes highly upregulated or suppressed by miglustat, D-PDMP and D-PPMP in MC3T3-E1 cells (cells were not treated with ascorbic acid and $\beta$-glycerophosphate). (A) Genes that were suppressed by all three inhibitors, with fold change $>1.5$ and value of the control sample in the raw data $>50$. (B) Genes that were upregulated by all three inhibitors, with fold change $>1.5$, and values of the inhibitors' samples in the raw data $>50$.

siRNA (Silencer Select Negative Control \#1; Life Technologies) was used. Cells were transiently transfected with siRNA in OptiMEM I medium with Lipofectamine RNAiMAX (Life Technologies). The efficiency of silencing was evaluated by qPCR $48 \mathrm{~h}$ after transfection. The cells were plated at $0.5 \times 10^{5}$ cells per $60-\mathrm{mm}$ dish $48 \mathrm{~h}$ after transfection and cultured for 2 or 3 days. After staining the cells with trypan blue, the number of live and dead cells was counted using a hemacytometer.

Statistical analysis. All data are expressed as mean \pm standard deviation (SD). For comparison between two samples, statistical significance was evaluated using the Student's $t$-test; for multiple samples, one-way analysis of variance (ANOVA) followed by Dunnett post-hoc test were used. Significance was set at $p<0.05$. Single and double asterisks indicate $p<0.05$ and $p<0.01$, respectively.

\section{Results}

Expression of Ugcg, GDla and Gb4 during osteoblast differentiation, and suppression of proliferation by GCS inhibitors in MC3T3-E1 cells. GD1a and Gb4 were expressed in MC3T3-E1 cells (Figure 1B). After induction of MC3T3E1 cells to mature osteoblasts, the expression level of Osteocalcin mRNA was significantly upregulated on days 14 and 21, while the expression level of $U g c g$ was significantly downregulated on days 7, 14 and 21 (Figure 2A). Expression levels of GD1a and Gb4 also significantly decreased after induction of osteoblast maturation (Figure 2B, C). The proliferation of mature osteoblasts was significantly lower than that of immature MC3T3-E1 cells (Figure 2D). These results suggest that GCS, which is essential for the expression of GD1a and Gb4, may be involved in the proliferation of osteoblasts. Administration of $50 \mu \mathrm{M}$ miglustat to MC3T3E1 cells for 4 days significantly reduced expression of GD1a and Gb4 (Figure 3A). Administration of 5-20 $\mu \mathrm{M}$ D-PDMP for 4 days significantly decreased expression of GD1a and Gb4 in a dose dependent manner (Figure 3B). Expression levels of GD1a and Gb4 were significantly reduced by 0.1 5.0 and 0.5-5.0 $\mu \mathrm{M}$ D-PPMP administration for 4 days, respectively (Figure 3C). The number of live cells was 

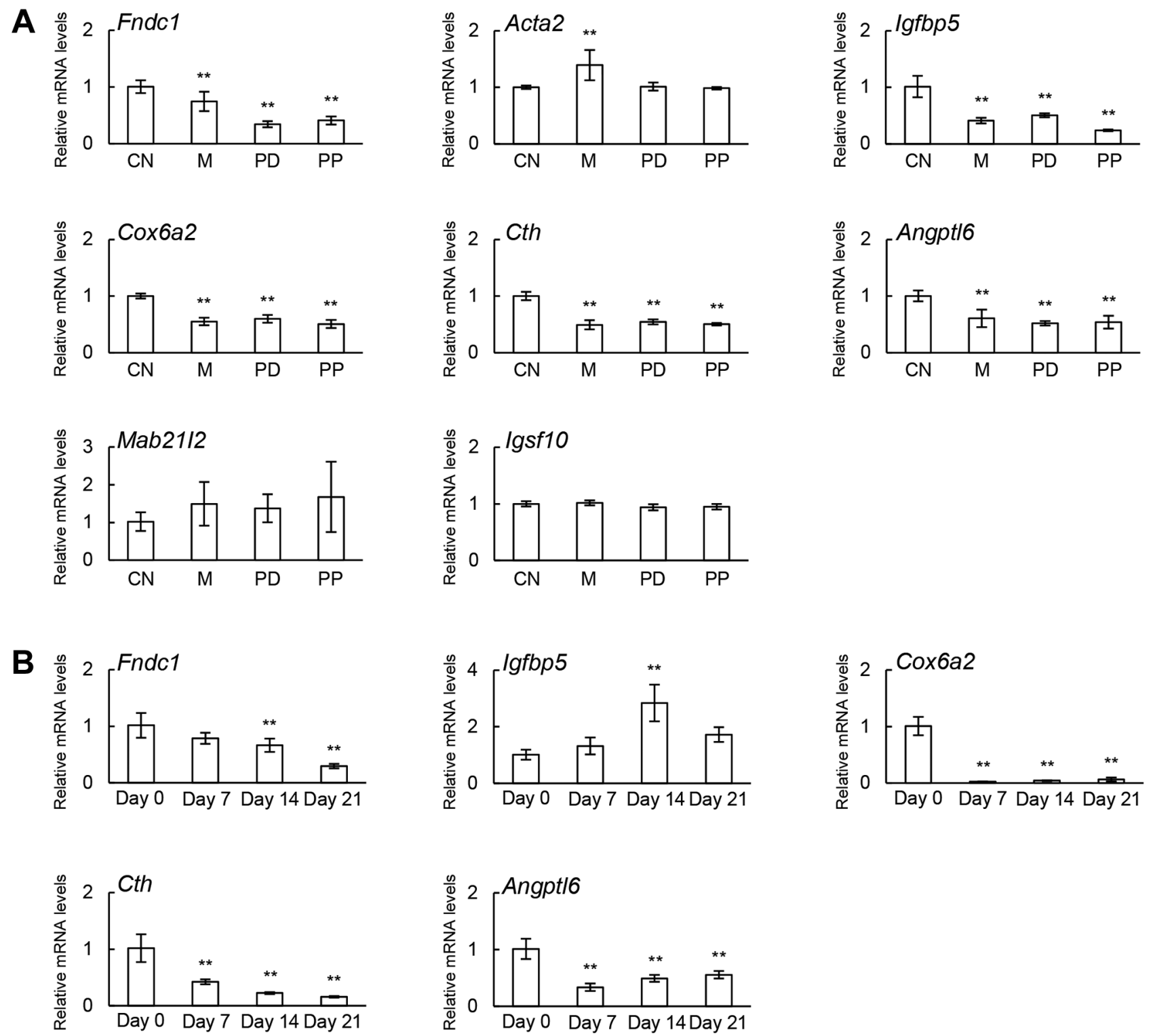

Figure 6. qPCR-based mRNA expression levels of candidate genes downregulated by miglustat, D-PDMP and D-PPMP in MC3T3-E1 cells. CN: Control sample; M: miglustat-treated sample; PD: D-PDMP-treated sample; PP: D-PPMP-treated sample. (A) mRNA expression levels of Fndc1, Acta2, Igfbp5, Cox6a2, Cth, Mymk, Angptl6, Mab21l2 and Igsf10 in MC3T3-E1 cells (cells were not treated with ascorbic acid and $\beta$ glycerophosphate) treated with the inhibitors ( $n=5)$. (B) mRNA expression levels of Fndc1, Igfbp5, Cox6a2, Cth, and Angptl6 in MC3T3-E1 cells on days $0,7,14$ and 21 after induction of osteoblastogenesis $(n=4)$. Data is expressed as mean \pm standard deviation. $* p<0.05$ and $* * p<0.01$.

significantly reduced in response to $10-50 \mu \mathrm{M}$ miglustat, 10 $20 \mu \mathrm{M}$ D-PDMP and 0.5-5.0 $\mu \mathrm{M}$ D-PPMP (Figure 4A, C and E). On the other hand, the inhibitors of GCS did not alter cell mortality (Figure 4B, D and F).

Prediction of genes involved in the response to miglustat, $D$ PDMP and D-PPMP in MC3T3-E1 cells. Genome-wide mRNA expression analysis predicted genes upregulated or downregulated by the three inhibitors (Figure 5). The analysis predicted nine downregulated genes [fibronectin type III domain containing 1 ( $F n d c l)$, actin, alpha 2, smooth muscle, aorta (Acta2), insulin-like growth factor binding protein 5 (Igfbp5), cytochrome c oxidase subunit 6A2 (Cox6a2), cystathionase $(C t h)$, myomaker, myoblast fusion factor (Mymk), angiopoietin-like 6 (Angptl6), mab-21-like 2 (Mab2112) and immunoglobulin superfamily, member 10 (Igsf10)] and 10 upregulated genes [mitochondrial ribosome associated GTPase 2 (Mtg2), nuclear receptor subfamily 4, 

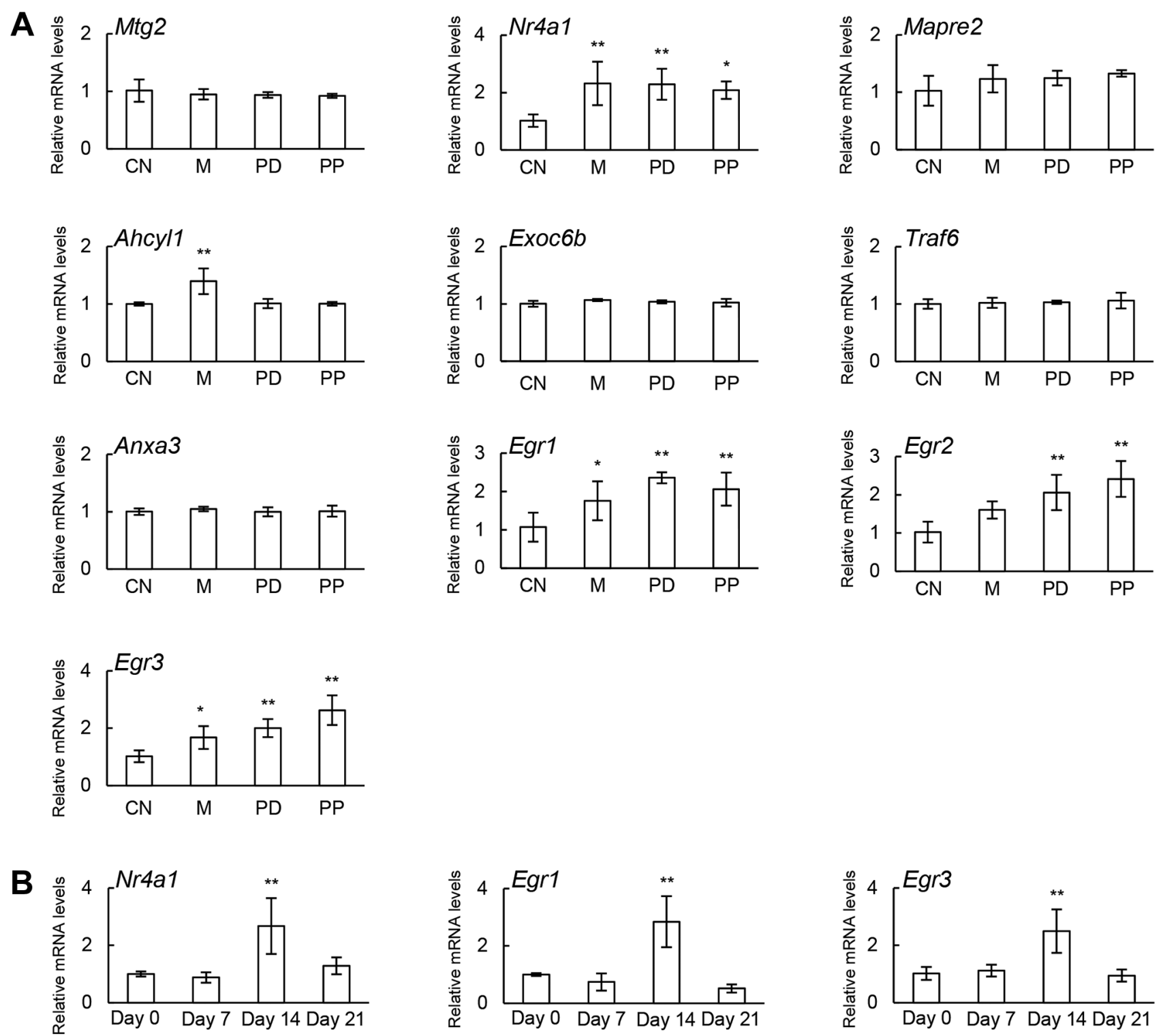

Figure 7. qPCR-based mRNA expression levels of candidate genes upregulated by miglustat, D-PDMP and D-PPMP in MC3T3-E1 cells. CN: Control sample; M: miglustat-treated sample; PD: D-PDMP-treated sample; PP: D-PPMP-treated sample. (A) mRNA expression levels of Mtg2, Nr4a1, Mapre2, Ahcyl1, Exoc6b, Traf6, Anxa3, Egr1, Egr2, and Egr3 in MC3T3-E1 cells (cells were not treated with ascorbic acid and $\beta$-glycerophosphate) treated with the inhibitors $(n=5)$. (B) mRNA expression levels of Nr4a1, Egr1, and Egr3 in MC3T3-E1 cells on days 0, 7, 14 and 21 after induction of osteoblastogenesis $(n=4)$. Data is expressed as mean \pm standard deviation. $* p<0.05$ and $* * p<0.01$.

group A, member $1(\mathrm{Nr} 4 \mathrm{al})$, microtubule-associated protein, RP/EB family, member 2 (Mapre2), S-adenosylhomocysteine hydrolase-like 1 (Ahcyll), exocyst complex component 6B (Exoc6b), TNF receptor-associated factor 6 (Traf6), annexin A3 (Anxa3), early growth response 1 (Egrl), Egr2, and Egr3].

Genes upregulated or downregulated by miglustat, D-PDMP, and D-PPMP in MC3T3-E1 cells. The expression levels of mRNA predicted by microarray were confirmed by qPCR.
Among the nine predicted genes suppressed by the inhibitors, mRNA expression levels of Fndcl, Igfbp5, Cox6a2, Cth, and Angptl6 were suppressed by all three (Figure 6A). Of note, Mymk mRNA was not detected in MC3T3-E1 cells. mRNA expression levels of Fndcl, Cox6a2, Cth, and Angptl6 were downregulated after induction of osteoblast maturation, while Igfbp5 was upregulated (Figure 6B). Among the 10 genes predicted to be upregulated by the inhibitors, mRNA expression levels of 

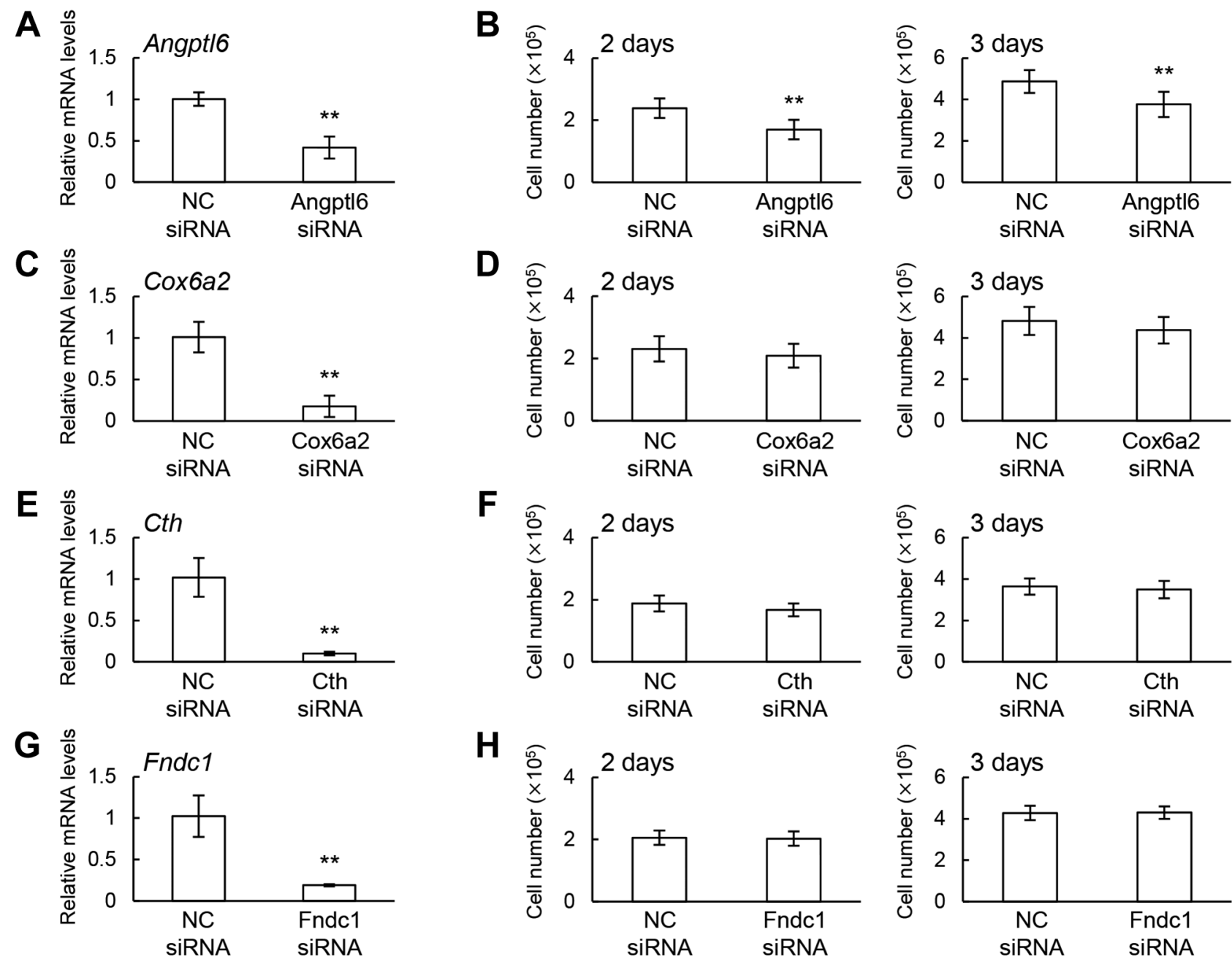

Figure 8. Effects of partial silencing of Angptl6, Cox6a2, Cth and Fndc1 on the proliferation of MC3T3-E1 cells. NC=Negative Control. (A) Reduction of Angptl6 by siRNA treatment $(n=3)$. (B) Suppression of cell growth by Angptl6 siRNA treatment $(n=6)$. Cells were plated at $0.5 \times 10^{5}$ cells per 60-mm dish $48 \mathrm{~h}$ after transfection and cultured for 2 (left panel) or 3 (right panel) days. (C) Reduction of Cox6a 2 by siRNA treatment $(n=3)$. (D) No change in cell growth by Cox6a2 siRNA treatment $(n=6)$. Cells were plated at $0.5 \times 10^{5}$ cells per 60 -mm dish 48 h after transfection and cultured for 2 (left panel) or 3 (right panel) days. (E) Reduction of Cth by siRNA treatment $(n=3)$. ( $F)$ No change in cell growth by Cth siRNA treatment $(n=6)$. Cells were plated at $0.5 \times 10^{5}$ cells per $60-\mathrm{mm}$ dish $48 \mathrm{~h}$ after transfection and cultured for 2 (left panel) or 3 (right panel) days. $(G)$ Reduction of Fndcl by siRNA treatment $(n=3)$. $(H)$ No change in cell growth by Fndc1 siRNA treatment $(n=6)$. Cells were plated at $0.5 \times 10^{5}$ cells per 60-mm dish $48 \mathrm{~h}$ after transfection and cultured for 2 (left panel) or 3 (right panel) days. Data are expressed as mean \pm standard deviation. $* p<0.05$ and $* * p<0.01$, respectively.

$N r 4 a 1, E g r l$, and $E g r 3$ were upregulated by all three (Figure 7A). mRNA expression levels of Nr4al, Egrl, and Egr3 were upregulated at day 14 and downregulated at day 21 after induction of osteoblastogenesis (Figure 7B).

Decrease in proliferation of MC3T3-E1 cells by partial silencing of Angptl6. To examine the involvement of Angt16, Cox6a2, Cth, and Fndc1 in proliferation of osteoblasts, partial gene silencing was conducted using siRNA in MC3T3-E1 cells. Proliferation was significantly reduced after knockdown of Angpt6 (Figure 8A, B), whereas knockdown of Cox6a2, Cth, and Fndcl did not affect the proliferation activity (Figure $8 \mathrm{C}-\mathrm{H}$ ).

\section{Discussion}

This study demonstrated that GCS regulates the proliferation of osteoblasts. GCS inhibition by miglustat, D-PDMP and DPPMP suppressed the expression of GD1a and Gb4 and the proliferation of MC3T3-E1 cells. Genome-wide microarray analysis predicted nine genes suppressed and 10 genes upregulated by all three inhibitors. Among the nine suppressed 


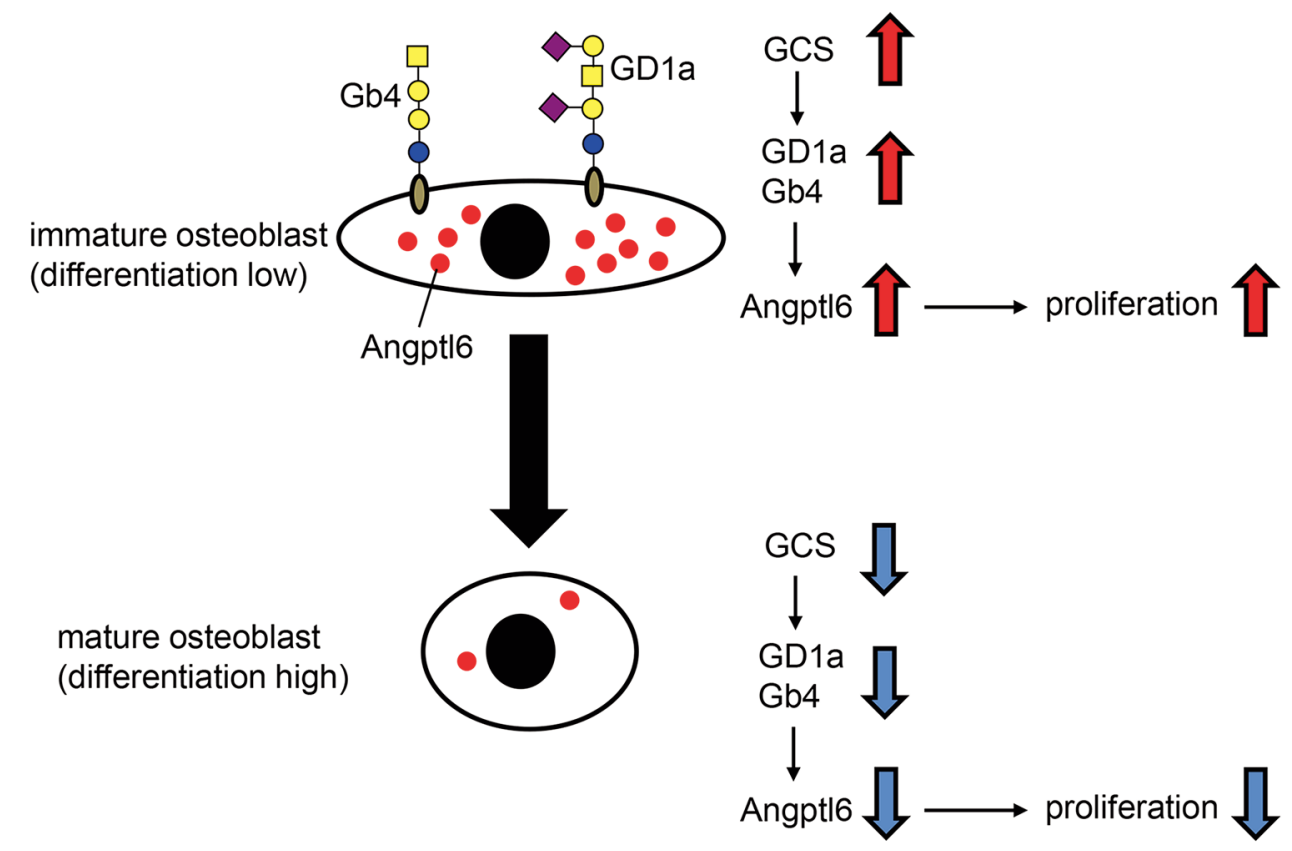

Figure 9. Schematic illustration of the proposed regulation of the proliferation of osteoblasts via GCS-regulated Angptl6. In immature osteoblasts, expression of Angptl6 is upregulated by the increase of GDIa and Gb4 via promotion of GCS, resulting in the increase in proliferation. On the other hand, in mature osteoblasts, expression of Angptl6 is downregulated by the decrease of GD1a and Gb4 via suppression of GCS, resulting in the decrease in proliferation.

genes, knockdown experiments by siRNA revealed that Angpt16 regulates the proliferation of MC3T3-E1 cells.

Glycosphingolipids are expressed in osteoblasts (6-9, 18, 19). GD1a has been reported to be involved in the differentiation of MSCs into osteoblasts (6-8). For instance, treatment of GD1a in human MSCs increased the phosphorylation level of epidermal growth factor receptors (EGFRs), leading to the induction of human MSCs into osteoblasts (6). Gb4 is expressed in mouse and human osteoblasts. Since deletion of Gb4 in mice results in the decrease of osteoblast numbers and suppression of osteoblast differentiation markers such as Runx2, alkaline phosphatase and osteocalcin (9), Gb4 expressed in osteoblasts may regulate proliferation or differentiation. However, the roles of these glycosphingolipids in osteoblast proliferation are not well understood. Here, administration of GCS inhibitors suppressed the expression of both GD1a and Gb4 and the proliferation of MC3T3-E1 cells. These results suggest that GD1a and Gb4 are involved in osteoblast proliferation. MC3T3-E1 cells, which are immature osteoblasts, expressed $U g c g$, GD1a and $\mathrm{Gb} 4$, and their expression decreased in mature osteoblasts. Furthermore, when immature osteoblasts differentiated into mature ones, cell growth was suppressed. Collectively, these results suggest that GD1a and Gb4 may promote the proliferation of osteoblasts.
Microarray analysis predicted genes suppressed or upregulated by all three inhibitors. Among the nine predicted genes suppressed by the inhibitors, qPCR confirmed that Fndc1, Igfbp5, Cox6a2, Cth, and Angptl6 were suppressed by all three inhibitors, which was consistent with the microarray analysis. Furthermore, among these five genes, the expression levels of Fndc1, Cox6a2, Cth, and Angptl6 were suppressed by induction of osteoblast maturation. The expression patterns of these genes were similar to that of $U g c g$, GD1a and Gb4. In order to examine the involvement of these genes in osteoblast proliferation, we conducted gene knockdown using individual siRNAs. Knockdown of these genes revealed that Angptl6 is involved in the promotion of osteoblast proliferation. Collectively, these results show that GCS regulates osteoblast proliferation through Angptl6.

Angptl6 belongs to the angiopoietin-like protein family, which is itself classified into Angptl1-7 (20, 21). Angptls possess both a coiled-coil domain at the $\mathrm{N}$-terminal and a fibrinogen-like domain at the C-terminal $(20,21)$. Angptl6 is known to be involved in angiogenesis and energy metabolism (22-24) and has been reported to lead to angiogenesis via the activation of ERK1/2-eNOS-NO signaling $(22,24)$. Furthermore, deletion of this gene in mice results in obesity and lipid accumulation in skeletal muscle (23). Expression of Angptl6 was also reported to be 
regulated by leptin (25). Although there have been no reports about the expression of Angplt6 in osteoblasts and its role in osteoblast proliferation, Angptl6 was reported to promote the proliferation of epidermal cells (26).

Among the 10 predicted genes upregulated by the inhibitors, expression levels of $\mathrm{Nr} 4 \mathrm{al}$, Egrl, and Egr3 were upregulated by all three, which was consistent with the microarray analysis. Furthermore, expression of these genes increased 14 days and decreased 21 days after induction of osteogenesis. Since these three genes were upregulated by the inhibitors and showed increased expression after induction of osteogenesis, they may be involved in osteoblast differentiation. Indeed, among these genes, it was reported that Egrl promotes differentiation of osteoblasts via soluble Klotho which is a type I transmembrane protein that is involved in aging (27). Nevertheless, osteoblast-specific deletion of $\mathrm{Nr} 4 \mathrm{a} 1$ in mice showed that $\mathrm{Nr} 4 \mathrm{a} 1$ is not involved in bone homeostasis (28).

In order to further evaluate how glycosphingolipids regulate the proliferation and differentiation of osteoblasts, additional experiments are required. Firstly, although GCS inhibition suppressed osteoblast proliferation, it will be necessary to clarify which glycosphingolipids expressed in osteoblasts are involved in proliferation. Secondly, GCS promotes osteoblast proliferation through Angptl6, and the expression of both $U g c g$ and Angptl6 decreases during maturation of osteoblasts. Whether these observations indicate that glycosphingolipids negatively regulate osteoblast differentiation needs to be evaluated. Thirdly, since Nr4al, Egrl, and Egr3 were upregulated by the inhibitors and increased with the decrease of glycosphingolipids after the induction of osteoblast maturation, the involvement of these molecules in osteoblast differentiation requires further investigation. Although the mechanism by which glycosphingolipids regulate the proliferation and differentiation of osteoblasts is not fully understood, this study provides the first evidence of the regulatory mechanisms of GCS in osteoblast proliferation. In summary, this study demonstrated that GCS, which is essential for the production of GD1a and Gb4, regulates the proliferation of mouse osteoblasts via Angptl6 (Figure 9).

\section{Conflicts of Interest}

The Authors declare no conflicts of interest.

\section{Authors' Contributions}

Y.M., K.H., H.K. (Hisataka Kondo), T.S., K.M., S.G. and A.T. designed the experiments. Y.M. K.H., H.K. (Hanami Kato), Y.T. and T.O. performed the experiments and analyzed the data. K.F. provided the anti-GD1a mAb. K.H. wrote the manuscript. All Authors read and approved the final manuscript.

\section{Acknowledgements}

This work was supported by JSPS KAKENHI Grant Number JP20K09899 to K.H. The authors thank Dr. Uchikawa, M. for providing anti-Gb4 $\mathrm{mAb}$ and Dr. Hiratsuka, M. at DNA Chip Research Inc. for microarray analysis.

\section{References}

1 Yu RK, Tsai YT and Ariga T: Functional roles of gangliosides in neurodevelopment: an overview of recent advances. Neurochem Res 37(6): 1230-1244, 2012. PMID: 22410735. DOI: $10.1007 / \mathrm{s} 11064-012-0744-\mathrm{y}$

2 Furukawa K, Ohmi Y, Kondo Y, Bhuiyan RH, Tajima O, Zhang $\mathrm{P}$, Ohkawa $\mathrm{Y}$ and Furukawa K: Elucidation of the enigma of glycosphingolipids in the regulation of inflammation and degeneration - Great progress over the last 70 years. Proc Jpn Acad Ser B Phys Biol Sci 95(3): 136-149, 2019. PMID: 30853699. DOI: 10.2183/pjab.95.011

3 Furukawa K, Ohmi Y, Ohkawa Y, Bhuiyan RH, Zhang P, Tajima O, Hashimoto N, Hamamura K and Furukawa K: New era of research on cancer-associated glycosphingolipids. Cancer Sci 110(5): 15441551, 2019. PMID: 30895683. DOI: 10.1111/cas.14005

4 Komatsuya K, Kaneko K and Kasahara K: Function of platelet glycosphingolipid microdomains/lipid rafts. Int J Mol Sci 21(15): 5539, 2020. PMID: 32748854. DOI: 10.3390/ ijms21155539

5 Yo S, Hamamura K, Mishima Y, Hamajima K, Mori H, Furukawa K, Kondo H, Tanaka K, Sato T, Miyazawa K, Goto S and Togari A: Deficiency of GD3 synthase in mice resulting in the attenuation of bone loss with aging. Int J Mol Sci 20(11): 2825, 2019. PMID: 31185614. DOI: 10.3390/ijms20112825

6 Kim SM, Jung JU, Ryu JS, Jin JW, Yang HJ, Ko K, You HK, Jung KY and Choo YK: Effects of gangliosides on the differentiation of human mesenchymal stem cells into osteoblasts by modulating epidermal growth factor receptors. Biochem Biophys Res Commun 371(4): 866-871, 2008. PMID: 18471991. DOI: $10.1016 /$ j.bbrc.2008.04.162

7 Yang HJ, Jung KY, Kwak DH, Lee SH, Ryu JS, Kim JS, Chang KT, Lee JW and Choo YK: Inhibition of ganglioside GD1a synthesis suppresses the differentiation of human mesenchymal stem cells into osteoblasts. Dev Growth Differ 53(3): 323-332, 2011. PMID: 21492147. DOI: 10.1111/j.1440-169X.2010.01240.x

8 Bergante S, Torretta E, Creo P, Sessarego N, Papini N, Piccoli M, Fania C, Cirillo F, Conforti E, Ghiroldi A, Tringali C, Venerando B, Ibatici A, Gelfi C, Tettamanti G and Anastasia L: Gangliosides as a potential new class of stem cell markers: the case of GD1a in human bone marrow mesenchymal stem cells. J Lipid Res 55(3): 549-560, 2014. PMID: 24449473. DOI: 10.1194/jlr.M046672

9 Hamamura K, Hamajima K, Yo S, Mishima Y, Furukawa K, Uchikawa M, Kondo Y, Mori H, Kondo H, Tanaka K, Miyazawa $\mathrm{K}$, Goto $\mathrm{S}$ and Togari A: Deletion of Gb3 synthase in mice resulted in the attenuation of bone formation via decrease in osteoblasts. Int J Mol Sci 20(18): 4619, 2019. PMID: 31540393. DOI: $10.3390 /$ ijms 20184619

10 Ichikawa S, Ozawa K and Hirabayashi Y: Molecular cloning and characterization of the mouse ceramide glucosyltransferase gene. Biochem Biophys Res Commun 253(3): 707-711, 1998. PMID: 9918791. DOI: 10.1006/bbrc.1998.9855 
11 Ichikawa S and Hirabayashi Y: Glucosylceramide synthase and glycosphingolipid synthesis. Trends Cell Biol 8(5): 198-202, 1998. PMID: 9695839. DOI: 10.1016/s0962-8924(98)01249-5

12 Nordström V, Willershäuser M, Herzer S, Rozman J, von Bohlen Und Halbach O, Meldner S, Rothermel U, Kaden S, Roth FC, Waldeck C, Gretz N, de Angelis MH, Draguhn A, Klingenspor M, Gröne HJ and Jennemann R: Neuronal expression of glucosylceramide synthase in central nervous system regulates body weight and energy homeostasis. PLoS Biol 11(3): e1001506, 2013. PMID: 23554574. DOI: 10.1371/journal.pbio.1001506

13 Jennemann R, Kaden S, Sandhoff R, Nordström V, Wang S, Volz M, Robine S, Amen N, Rothermel U, Wiegandt H and Gröne HJ: Glycosphingolipids are essential for intestinal endocytic function. J Biol Chem 287(39): 32598-32616, 2012. PMID: 22851168. DOI: $10.1074 /$ jbc.M112.371005

14 Jung JU, Ko K, Lee DH, Ko K, Chang KT and Choo YK: The roles of glycosphingolipids in the proliferation and neural differentiation of mouse embryonic stem cells. Exp Mol Med 41(12): 935-945, 2009. PMID: 19745600. DOI: 10.3858/emm. 2009.41.12.099

15 Jang HJ, Lim S, Kim JM, Yoon S, Lee CY, Hwang HJ, Shin JW, Shin KJ, Kim HY, Park KI, Nam D, Lee JY, Yea K, Hirabayashi Y, Lee YJ, Chae YC, Suh PG and Choi JH: Glucosylceramide synthase regulates adipo-osteogenic differentiation through synergistic activation of PPAR $\gamma$ with GlcCer. FASEB J 34(1): 1270-1287, 2020. PMID: 31914593. DOI: 10.1096/fj.201901437R

16 Zhao H, Przybylska M, Wu IH, Zhang J, Maniatis P, Pacheco J, Piepenhagen P, Copeland D, Arbeeny C, Shayman JA, Aerts JM, Jiang C, Cheng SH and Yew NS: Inhibiting glycosphingolipid synthesis ameliorates hepatic steatosis in obese mice. Hepatology 50(1): 85-93, 2009. PMID: 19444873. DOI: 10.1002/hep.22970

17 Cabrera-Salazar MA, Deriso M, Bercury SD, Li L, Lydon JT, Weber W, Pande N, Cromwell MA, Copeland D, Leonard J, Cheng SH and Scheule RK: Systemic delivery of a glucosylceramide synthase inhibitor reduces CNS substrates and increases lifespan in a mouse model of type 2 Gaucher disease. PLoS One 7(8): e43310, 2012. PMID: 22912851. DOI: 10.1371/journal.pone.0043310

18 Moussavou G, Kwak DH, Lim MU, Kim JS, Kim SU, Chang KT and Choo YK: Role of gangliosides in the differentiation of human mesenchymal-derived stem cells into osteoblasts and neuronal cells. BMB Rep 46(11): 527-532, 2013. PMID: 24152915. DOI: 10.5483/bmbrep.2013.46.11.179

19 Reed MC, Schiffer C, Heales S, Mehta AB and Hughes DA: Impact of sphingolipids on osteoblast and osteoclast activity in Gaucher disease. Mol Genet Metab 124(4): 278-286, 2018. PMID: 29934064. DOI: 10.1016/j.ymgme.2018.06.007

20 Hato T, Tabata M and Oike Y: The role of angiopoietin-like proteins in angiogenesis and metabolism. Trends Cardiovasc Med 18(1): 6-14, 2008. PMID: 18206803. DOI: 10.1016/j.tcm. 2007.10.003
21 Kadomatsu T, Tabata M and Oike Y: Angiopoietin-like proteins: emerging targets for treatment of obesity and related metabolic diseases. FEBS J 278(4): 559-564, 2011. PMID: 21182596. DOI: 10.1111/j.1742-4658.2010.07979.x

22 Oike Y, Ito Y, Maekawa H, Morisada T, Kubota Y, Akao M, Urano T, Yasunaga $\mathrm{K}$ and Suda T: Angiopoietin-related growth factor (AGF) promotes angiogenesis. Blood 103(10): 3760-3765, 2004. PMID: 14764539. DOI: 10.1182/blood-2003-04-1272

23 Oike Y, Akao M, Yasunaga K, Yamauchi T, Morisada T, Ito Y, Urano T, Kimura Y, Kubota Y, Maekawa H, Miyamoto T, Miyata K, Matsumoto S, Sakai J, Nakagata N, Takeya M, Koseki H, Ogawa Y, Kadowaki T and Suda T: Angiopoietin-related growth factor antagonizes obesity and insulin resistance. Nat Med 11(4): 400-408, 2005. PMID: 15778720. DOI: 10.1038/nm1214

24 Urano T, Ito Y, Akao M, Sawa T, Miyata K, Tabata M, Morisada T, Hato T, Yano M, Kadomatsu T, Yasunaga K, Shibata R, Murohara T, Akaike T, Tanihara H, Suda $\mathrm{T}$ and Oike $\mathrm{Y}$ : Angiopoietin-related growth factor enhances blood flow via activation of the ERK1/2-eNOS-NO pathway in a mouse hind-limb ischemia model. Arterioscler Thromb Vasc Biol 28(5): 827-834, 2008. PMID: 18258819. DOI: 10.1161/ATVBAHA.107.149674

25 Kim MJ, Namkung J, Chang JS, Kim SJ, Park KS and Kong ID: Leptin regulates the expression of angiopoietin-like 6. Biochem Biophys Res Commun 502(3): 397-402, 2018. PMID: 29852166. DOI: $10.1016 /$ j.bbrc.2018.05.180

26 Oike Y, Yasunaga K, Ito Y, Matsumoto S, Maekawa H, Morisada T, Arai F, Nakagata N, Takeya M, Masuho Y and Suda T: Angiopoietin-related growth factor (AGF) promotes epidermal proliferation, remodeling, and regeneration. Proc Natl Acad Sci U.S.A. 100(16): 9494-9499, 2003. PMID: 12871997. DOI: 10.1073/pnas.1531901100

27 Toan NK, Tai NC, Kim SA and Ahn SG: Soluble Klotho regulates bone differentiation by upregulating expression of the transcription factor EGR-1. FEBS Lett 594(2): 290-300, 2020. PMID: 31536138. DOI: 10.1002/1873-3468.13613

28 Scholtysek C, Ipseiz N, Böhm C, Krishnacoumar B, Stenzel M, Czerwinski T, Palumbo-Zerr K, Rothe T, Weidner D, Klej A, Stoll C, Distler J, Tuckermann J, Herrmann M, Fabry B, Goldmann WH, Schett G and Krönke G: NR4A1 regulates motility of osteoclast precursors and serves as target for the modulation of systemic bone turnover. J Bone Miner Res 33(11): 2035-2047, 2018. PMID: 29949664. DOI: 10.1002/jbmr.3533

Received July 15, 2021

Revised August 23, 2021

Accepted August 30, 2021 